\title{
Automated Planning with Induced Qualitative Models in Dynamic Robotic Domains
}

\author{
Domen Šoberl \\ University of Primorska, Faculty of Mathematics, Natural Sciences and Information Technologies, Koper, Slovenia \\ University of Ljubljana, Faculty of Computer and Information Science, Ljubljana, Slovenia \\ E-mail: domen.soberl@famnit.upr.si
}

\section{Thesis summary}

Keywords: learning qualitative models, qualitative reasoning, qualitative simulation, qualitative planning, explainable control strategies

Received: September 22, 2021

\begin{abstract}
Various methods of learning qualitative models by autonomous robots have previously been proposed as a viable alternative to traditional numerical modeling, but an efficient way of using such models for planning still remained an open problem. This paper summarizes a doctorat thesis, which proposes a novel domainindependent qualitative approach to automated planning and execution of robotic plans. The proposed method is demonstrated in five different robotic domains.
\end{abstract}

Povzetek: Različne metode učenja kvalitativnih modelov $v$ avtonomni robotiki so bile $v$ preteklosti predlagane kot možna alternativa tradicionalnemu numeričnemu modeliranju, toda učinkovit način uporabe takšnih modelov za planiranje je še vedno ostal odprt problem. Ta članek povzema doktorska disertacijo, ki predlaga nov, domensko neodvisen kvalitativen pristop $k$ avtomatiziranemu planiranju in izvedbi robotskih planov. Disertacija predlagano metodo demonstrira $v$ petih različnih robotskih domenah.

\section{Introduction}

Cognitive robotics aims to bring robots out of their typical industrial environments and closer to a human type of reasoning and cognition. Some researchers in this area have proposed the use of qualitative modeling as a viable alternative to the traditional numerical modeling. Various experiments showed a better training sample efficiency and a lower susceptibility to noise when learning qualitatively. Moreover, since qualitative models tend to be closer to human intuition, they can provide a more comprehensive explanation of the learned theory.

Qualitative models may have a certain explanatory significance to humans, but to robots, they are generally far less useful than numerical models. To perform some task, a robot needs to plan, and planning in continuous robotic domains is typically a numerical problem. Qualitative models abstract away most if not all numerical data, so an important part of information needed by a planner is missing from the model.

To answer the question of how qualitative models can still assist with the robotic performance, Wiley et al. [1] proposed to qualitatively constrain the search space of a trial-and-error learning, thus shorten the time to find a working solution in a numerical way. However, the question whether qualitative models could be used to plan and execute a robotic task without additional numerical training still remained open.

This paper summarizes a doctoral thesis [2], which shows that certain robotic tasks can be planned and executed within continuous domains using qualitative information alone. The performance can improve over time through on-line numerical adaptation. The proposed method was demonstrated in five different robotic domains.

\section{Methodology}

The thesis focuses on a specific type of qualitative models that encode information through monotonic qualitative constraints (MQC), which were proposed by Benjamin Kuipers [3]. These constraints abstract differentiable functions of one or more variables to intervals of monotonically increasing and decreasing values. A system modeled in such a way can be simulated qualitatively using Kuipers' program called QSIM. The thesis shows how QSIM can be transformed into a qualitative robotic planner that can devise symbolic plans based on a given qualitative model and with some given initial and goal conditions. Such plans determine a sequence of symbolic actions that should be taken (e.g. accelerate, turn right, etc.), but do not determine their numerical outputs and durations.

To execute qualitative plans on a numerical system, the thesis proposes a novel algorithm that reactively decides the numerical outputs based on the current and past numerical observations, while following a qualitative plan. $\mathrm{Nu}$ merical observations such as speeds and accelerations of individual robot's attributes (typically translations and ro- 
tations of the robot or its individual parts) are used by the algorithm to internally construct a smooth hypersurface, to which it maps the planned qualitative states, so that the targeted state is always lower on the hypersurface than the current state. The output signals are then determined dynamically by following the steepest descent along the hypersurface. The performance of the algorithm has been successfully evaluated for real-time execution on embedded systems.

To demonstrate domain independence of the proposed method, the implementation strictly separates the method from the model. A new language called QDDL (Qualitative Domain Description Language) is defined and used to conduct the experiments.

\section{Results}

The proposed method was demonstrated with five different robotic problems, each exposing a different aspect of qualitative planning and execution. Some experiments emphasize the dynamic adaptability of qualitative models to the given environmental parameters, while others focus more on conceptual reasoning about the given numerical problem through qualitative planning.

Two-wheled autonomous vehicle learned a qualitative model of differential drive by motor babbling. Using the learned model the robot was able to pursuit a moving target and avoid collisions [4].

Pushing objects by a robot. A wheeled robot learned a qualitative model that encoded the physics behind pushing a rectangular box. Qualitative abstraction made the learned model general enough to enable the robot to push boxes of different shapes to the designated locations. [5]

Flying a quadcopter. A quadcopter autonomously learned a qualitative model for navigating through space and qualitatively planned and executed an escape out of an enclosed space. [6]

Controlling the cart-pole system. The well known inverted pendulum problem was implemented as a cart-andpole system, which learned to stabilize within seconds. The devised qualitative plan offered a comprehensive explanation of the used control strategy. [7]

Discovering bipedal walking. A humanoid robot was given a task to move forward a certain distance. As a means to achieve this goal, the robot discovered a qualitative concept of bipedal walking, which was successfully executed.

\section{Conclusion}

The thesis proposes a novel approach to qualitative planning and plan execution in continuous robotic domains. The proposed method is domain independent and allows qualitative models to be used without additional numerical training. While the proposed qualitative approach might not be feasible for all robotic problems, it has been successfully demonstrated with a variety of problems on different types of robots. The results were published in several peerreviewed publications.

\section{References}

[1] Wiley T., Sammut C., Bratko I. (2016) A Planning and Learning Hierarchy using Qualitative Reasoning for the On-Line Acquisition of Robotic Behaviors, Advances in Cognitive Systems 4, pp. 93-112.

[2] Šoberl, D. (2021) Automated planning with induced qualitative models in dynamic robotic domains, $\mathrm{PhD}$ thesis, University of Ljubljana. https://repozitorij.unilj.si/IzpisGradiva.php?id=126285

[3] Kuipers B. (1986) Qualitative simulation, Artificial Intelligence 29(3), pp. 289-338, DOI: 10.1016/00043702(86)90073-1

[4] Šoberl D., Bratko I. (2017) Reactive Motion Planning with Qualitative Constraints, Advances in Artificial Intelligence: From Theory to Practice. IEA/AIE 2017. Lecture Notes in Computer Science, vol 10350, Springer, Cham, pp. 41-50. DOI: 10.1007/978-3319-60042-0_5

[5] Šoberl D., Žabkar J., Bratko I. (2015) Qualitative Planning of Object Pushing by a Robot, Foundations of Intelligent Systems. ISMIS 2015. Lecture Notes in Computer Science, vol 9384, Springer, Cham, pp. 410-419. DOI: 10.1007/978-3-319-25252-0_44

[6] Šoberl D., Žabkar J., Bratko I. (2020) Learning to Control a Quadcopter Qualitatively, Journal of Intelligent \& Robotic Systems 100(3), pp. 1097-1110. DOI: 10.1007/s10846-020-01228-7

[7] Šoberl D., Bratko I. (2019) Learning Explainable Control Strategies Demonstrated on the Pole-andCart System, Advances and Trends in Artificial Intelligence. From Theory to Practice. IEA/AIE 2019. Lecture Notes in Computer Science, vol 11606, Springer, Cham, pp. 483-494. DOI: 10.1007/978-3030-22999-3_42 